\title{
Bacterias nitrificantes cultivables de la zona limnética del lago de Tota, Boyacá
}

\section{Cultivable nitrifying bacteria of the limnetic zone of Tota lake, Boyacá, Colombia}

\author{
Julián Esteban Másmela-Mendoza; Luz Marina Lizarazo-Forero²*; Nelson Javier Aranguren Riaño ${ }^{3}$
}

\begin{abstract}
'Biólogo. Universidad Pedagógica y Tecnológica de Colombia, Facultad de Ciencias, Grupo de Investigación Biología Ambiental. Tunja, Boyacá, Colombia. e-mail: julian.masmela@uptc.edu.co; Dhttps://orcid.org/0000-0001-9841-8242

²Bacterióloga y Laboratorista clínico. Ph.D. Universidad Pedagógica y Tecnológica de Colombia, Facultad de Ciencias, Escuela de Biología, Grupo de Investigación Biología Ambiental. Tunja, Boyacá, Colombia. e-mail: luz.lizarazo@uptc.edu.co; Dhttp://orcid.org/0000-0002-7849-7876

${ }^{3}$ Licenciado en Biología. Ph.D. Universidad Pedagógica y Tecnológica de Colombia, Facultad de Ciencias, Escuela de Biología, Grupo de Investigación Unidad de Ecología en Sistemas Acuáticos UDESA. Tunja, Boyacá, Colombia. e-mail: nelson.aranguren@uptc.edu.co; Dhttps://orcid.org/0000-0003-0117-1015
\end{abstract}

*autor de correspondencia: bio.ambient@uptc.edu.co

Cómo citar: Másmela-Mendoza, J.E.; Lizarazo-Forero, L.M.; Aranguren Riaño, N.J. 2019. Bacterias nitrificantes cultivables de la zona limnética del lago de Tota, Boyacá. Rev. U.D.C.A Act. \& Div. Cient.22(2):e1378. http://doi.org/10.31910/rudca.v22.n2.2019.1378

Artículo de acceso abierto publicado por Revista U.D.C.A Actualidad \& Divulgación Científica, bajo una licencia Creative Commons CC BY-NC 4.0

Recibido: Julio 17 de 2019

Aceptado: Noviembre 1 de 2019

Editado por: Ingeborg Zenner de Polanía

\section{RESUMEN}

Las actividades de producción piscícola en el Lago de Tota, Boyacá aumentan las concentraciones de amonio y de nitrato, nutrientes que están acelerando los procesos de eutrofización. Entre las comunidades microbianas que regulan la entrada de nitrógeno alóctono figuran las bacterias nitrificantes y la determinación de su abundancia en los ecosistemas es una medida de bioindicación de contaminación. El objetivo del estudio fue cuantificar y caracterizar bioquímicamente las bacterias nitrificantes cultivables de la zona limnética del lago. Para medir la abundancia, se usó la técnica de número más probable (NMP). Las muestras fueron tomadas en los sectores Lago Chico y Lago Grande, en zonas limnéticas, con actividad piscícola y sin intervención. Se midieron variables físicas y químicas in situ y se determinó la concentración de nutrientes en el laboratorio. Las mayores cuantificaciones de bacterias nitri- ficantes, se registraron en el periodo de baja precipitación y en el área de influencia de piscicultura. El grupo de bacterias oxidantes de amonio (BOA) y oxidantes de nitritos (BON) fue menor en la zona central de lago Grande respecto a zonas de piscifactorías de Hato Laguna y El Túnel. Se obtuvieron 14 aislamientos de bacterias nitrificantes, identificando los géneros Nitrosomonas spp. y Nitrobacter spp. Los cambios en la abundancia de BOA, se relacionaron con la alcalinidad, mientras que los valores de $\mathrm{BON}$, se correlacionaron con la conductividad eléctrica y el nitrógeno inorgánico disuelto. Una mayor abundancia de bacterias nitrificantes, se registró en las zonas limnéticas del lago, afectadas por la actividad piscícola, asociado al aumento de nutrientes disuelto en la columna de agua.

Palabras clave: eutrofización; piscifactorías; lagos de agua dulce; microbiología acuática; bacterias del ciclo del N. 


\section{ABSTRACT}

Fish production activities in Lake Tota, Boyacá are increasing concentrations of ammonium and nitrate, nutrients that are accelerating eutrophication processes. Some of the microbial communities that regulate the entry of allochthonous nitrogen are nitrifying bacteria, and the determination of their abundance in ecosystems is a measure of pollution bioindication. The objective of the study was to quantify and biochemically characterize the cultivable nitrifying bacteria of the limnetic zone of Lake Tota. The most probable number technique (MPN) was used to measure abundance. The samples were taken in the Lago Chico and Lago Grande sectors, in limnetic areas with fish activity and without intervention. Physical and chemical variables were measured in situ and the concentration of nutrients in the laboratory was determined. The highest quantifications of nitrifying bacteria were recorded in the area of influence of fish farming. The group of ammonium oxidizing bacteria (BOA) and nitrite oxidants (BON) was smaller in the central area of Lago Grande compared to fish farms in Hato Laguna and El Túnel. 14 isolates of nitrifying bacteria were obtained, genera Nitrosomonas spp. and Nitrobacter spp. Changes in BOA abundance were related to alkalinity, while BON values correlated with electrical conductivity and dissolved inorganic nitrogen. A greater abundance of nitrifying bacteria was recorded in the lake's limnetic areas affected by fish farming activity, associated with the increase in nutrients dissolved in the water column.

Keywords: eutrophication; fish farms; freshwater lakes; aquatic microbiology; bacteria of the $\mathrm{N}$ cycle.

\section{INTRODUCCIÓN}

Las bacterias nitrificantes son un ensamblaje de procariotas quimiolitoautótrofas, que se encuentran flotando en la columna de agua, conformando parte del bacterioplancton (Koops et al. 2006). La nitrificación es el resultado de la acción secuencial de dos grupos separados de bacterias, denominados bacterias oxidantes de amonio (BOA) y bacterias oxidantes de nitritos (BON), desarrollando el proceso, en forma sinérgica (Abeliovich, 2006; Koops et al. 2006). Las BOA oxidan el $\mathrm{NH}_{4}^{+}$a $\mathrm{NO}_{2}^{-}$y las BON continúan con el proceso de nitrificación al utilizar el nitrito producto del proceso anterior para oxidarlo a nitratos $\left(\mathrm{NO}_{3}\right)$, contribuyendo al balance de las especies químicas del $\mathrm{N}$ en los ecosistemas de agua dulce (French et al. 2012). De esta manera, las bacterias nitrificantes regulan los efectos y los riesgos de eutrofización, que puede tener la entrada del $\mathrm{N}$ alóctonos en los lagos meso-oligotróficos, ya que, mediante su metabolismo, consumen las formas inorgánicas y contribuyen al equilibrio del ciclo biogeoquímico (Xia et al. 2004; French et al. 2012).

Dentro de los principales géneros bacterianos que participan en la nitrificación en ecosistemas dulceacuícolas, se encuentran Nitrobacter, Nitrosomonas, Nitrosococcus y Nitrosolobus, siendo dominantes las especies de Nitrosomonas y Nitrobacter, dentro de las BOA y las BON, respectivamente (Koops \& Pommerening-Röser, 2001).
Hernández et al. (2013) clasificaron al lago de Tota como oligotrófico con tendencia a aumentar sus niveles de eutrofización; sin embargo, Muñoz-López et al. (2017) describen que el lago se encuentra en un estado trófico avanzado de oligotrófico a meso y eutrófico, generado por un aumento en las concentraciones de nitrógeno orgánico e inorgánico y una alta relación de N/P. Actividades antropogénicas, como el vertimiento de aguas residuales de los municipios aledaños, los procesos de escorrentía superficial y lixiviación de los fertilizantes químicos nitrogenados utilizados en los cultivos de cebolla y la contaminación por materia orgánica de distintas fuentes, podrían estar aumentando las concentraciones de amonio $\left(\mathrm{NH}_{4}{ }^{+}\right)$y de nitratos (NO3) en este lago (Abella \& Martínez, 2012). En el lago de Tota no se han realizado trabajos de investigación en microbiología mediante técnicas cultivables como no cultivables, es por ello, que establecer relaciones entre las abundancias de poblaciones microbianas, como las bacterias nitrificantes y los estados de eutrofización del ecosistema, es importante como contribución al conocimiento del lago y como alternativas en el uso de microorganismos en procesos de biorremediación, de las zonas contaminadas.

Descrita la problemática del ecosistema y la importancia del grupo microbiano esta investigación, se propuso realizar una cuantificación y caracterización de las bacterias oxidantes de amonio (BOA) y bacterias oxidantes de nitritos (BON), cultivables de la zona limnética del Lago de Tota.

\section{MATERIALES Y MÉTODOS}

Área de estudio. El Lago de Tota está localizado sobre la cordillera oriental colombiana, en el departamento de Boyacá, entre los 5²8', $5^{\circ} 39^{\prime} \mathrm{N}$ y $72^{\circ} 51^{\prime} \mathrm{W}$. El nivel máximo del lago corresponde a la cota de $3.015 \mathrm{~m}$ s.n.m, tiene un área de $60 \mathrm{~km}^{2}$, con una profundidad media y máxima de 30 y $60 \mathrm{~m}$, y una temperatura promedio de $11^{\circ} \mathrm{C}$ (Muñoz-López et al. 2017). El régimen de precipitaciones de la cuenca del Lago es unimodal para la región noreste y bimodal para el occidente, con un periodo seco de diciembre a marzo y un periodo de lluvias de abril a noviembre. Durante junio a agosto, se presentan las más altas precipitaciones (Udesa-Uptc \& CorpoBoyacá, 2015).

Diseño del muestreo. Se definieron cinco puntos distribuidos en las dos cubetas del lago: lago Chico y Lago Grande, de los cuales, en dos zonas (Hato Laguna y El Túnel), se realiza el cultivo de trucha arcoíris y los puntos restantes son zonas limnéticas centrales (Figura 1).

Se realizaron cuatro muestreos durante julio (2 muestras), agosto (1 muestra) y septiembre (1 muestra), del 2015, correspondientes a temporadas de transición de precipitaciones; julio se ha reportado como el mes más lluvioso en comparación con el de septiembre. Para el análisis de las poblaciones microbianas, en cada punto se tomaron muestras de la zona limnética de $5 \mathrm{~L}$ de agua a $2 \mathrm{~m}$ de profundidad, tomadas con una botella muestreadora horizontal (Wildco Wildlife Supply Company®) y reenvasadas en recipientes de vidrio estériles de $1000 \mathrm{~mL}$, transportadas en nevera con hielo seco hasta el laboratorio y procesadas en un rango de tiempo de máximo 12h. Entre cada toma de muestra la botella muestreadora fue enjuagada con $\mathrm{HCl} 1 \mathrm{~N}$ y agua destilada estéril (APHA, 2012). 

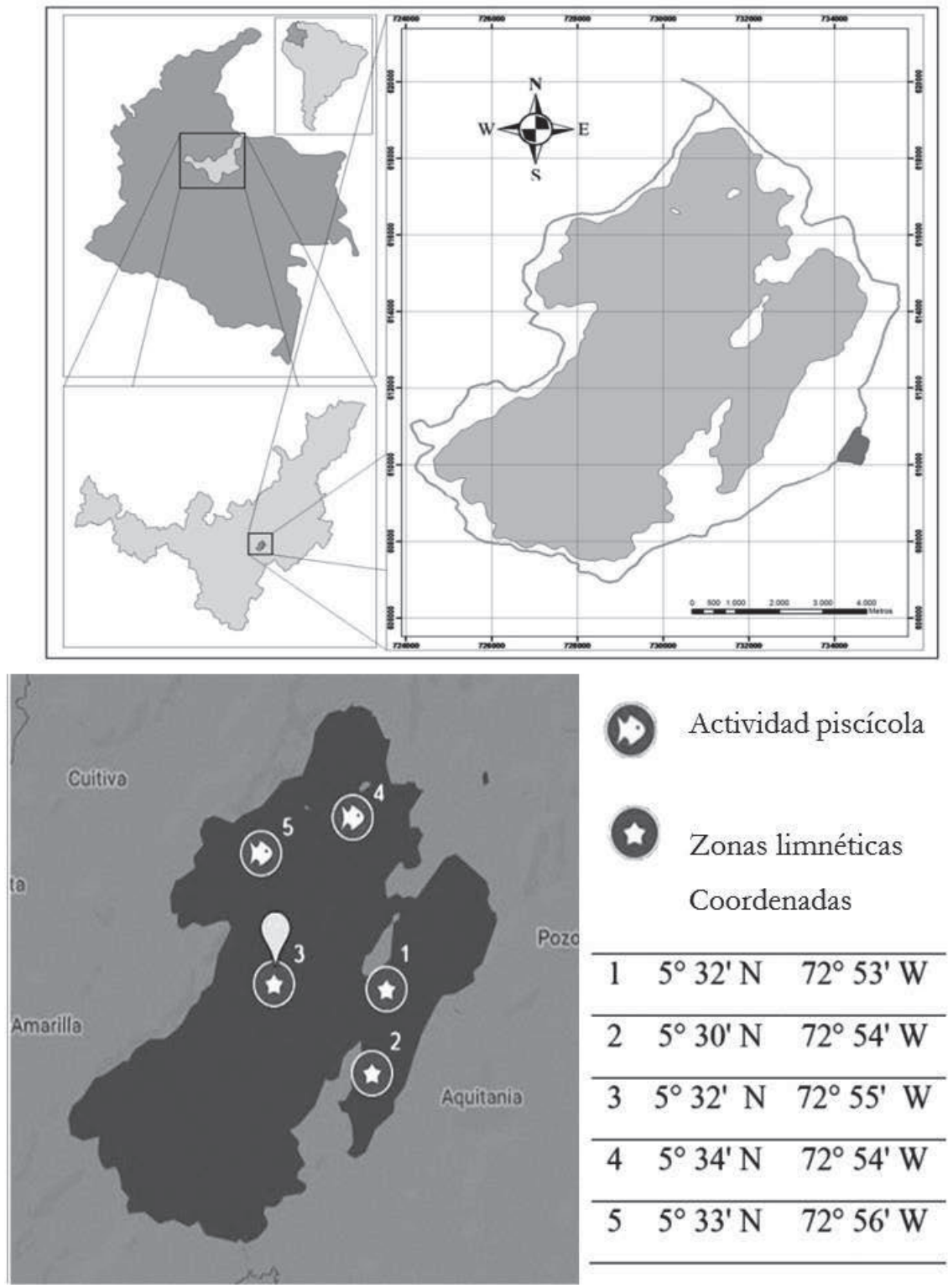

Figura 1. Áreas de muestra del lago Tota, Boyacá. 1) Lago Chico Centro; 2) Lago Chico Custodia; 3) Lago Grande Centro; 4) Grande Hato Laguna Lake; 5) Lago El Tunel. Fuente: Google Maps.

Medición de variables físicas y químicas in situ. Se registraron a $2 \mathrm{~m}$ de la superficie de cada punto de muestreo. La temperatura y la conductividad eléctrica con conductímetro YSI modelo 85. Las mediciones de $\mathrm{pH}$ con $\mathrm{pH}$ Hetro Schott instruments D-55014 Mainz. La alcalinidad y la dureza total con kits colorimétricos AquaMerck. El oxígeno disuelto y la saturación de oxígeno, se determinaron mediante el oxímetro YSI modelo 55/12 FT.

Concentraciones de nitrógeno y fósforo. Se tomaron $500 \mathrm{~mL}$ de muestras integradas de tres profundidades de la zona limnética, correspondientes a la superficie, según la profundidad Secchi, para un total de $1.500 \mathrm{~mL}$. Para obtener la fracción inorgánica de las muestras de agua, se filtraron $1000 \mathrm{~mL}$ a través de membranas de nitrocelulosa de $0,45 \mu \mathrm{m}$, por medio de bombas de vacío de polietileno, para separar la parte orgánica disuelta y particulada de los nutrientes totales. Las muestras, se guardaron en frascos de vidrio color ámbar y preservadas con ácido sulfúrico, hasta obtener un $\mathrm{pH}$ cercano a 2 y se mantuvieron en refrigeración hasta su análisis. La cuantificación de los nutrientes, se realizó mediante los métodos Macro-Kjeldahl SM 4500 - Norg C, 4500-NH3 B, F, para nitrógeno total y digestión colorimétrica del ácido ascórbico SM 4500-P B, E, para fósforo total (APHA, 2012).

Cuantificación de bacterias nitrificantes por el número más probable (NMP). Se usaron medios líquidos selectivos para los grupos funcionales: bacterias oxidantes de amonio (BOA) y 
bacterias oxidantes de nitritos (BON) (Schmidt \& Belser, 1982; Bock \& Koops, 1992; Koops \& Moller, 1992). La composición de los medios, se describe en la tabla 1 . Se sirvieron tubos con $9 \mathrm{~mL}$ del medio de cultivo y a cada uno se le adicionó $1 \mathrm{~mL}$ de la muestra previamente homogenizada, para obtener la dilución $10^{-1}$. A partir de esta primera dilución, se hicieron diluciones consecutivas directas en el medio. Para cada dilución, se sembraron tres réplicas. Los tubos inoculados fueron incubados a $30^{\circ} \mathrm{C}$, por 28 días (APHA, 2012). Para la lectura de los medios, se efectuaron pruebas colorimétricas con ácido sulfanílico y de N-dimetil-1-naftilamina, para la determinación de nitritos. Se catalogó como prueba positiva para BOA activas la formación de un color rosa después de un minuto de reacción Para la detección de nitratos, se usó difenilamina. El desarrollo de un color azul, se tomó como positivo para BON activas (APHA, 2012). Para comprobar el paso de amonio a nitritos en el caldo amonio, se usó el reactivo de Griess para la detección de nitritos, siendo positivo el desarrollo de una coloración roja después de 5 minutos. Para el cálculo del Número más probable (NMP)/1000mL, se contaron los tubos positivos por dilución y se analizaron en el programa informático de Most probable number (MPN) calculator versión 3.1 (acceso libre).

Caracterización de bacterias nitrificantes. Los tubos positivos para NMP, se subcultivaron en los medios BOA, agar amonio y en los medios selectivos Winodgradsky, Nitrosomonas spp. y Nitrobacter spp. (Tabla 1), con el fin de obtener colonias puras (Atlas, 2005). Las cajas fueron incubadas a $30^{\circ} \mathrm{C}$, durante 15 a 20 días; al finalizar la incubación, se realizaron descripciones macroscópicas y microscópicas de los aislamientos. Se emplearon las pruebas bioquímicas de requerimientos salinos (Atlas, 2005) y la actividad de ureasa, las cuales, son específicas para la caracterización de bacterias nitrificantes cultivables (Koops \& Pommerening-Röser, 2001). Además, se aplicaron las pruebas de motilidad, arabinosa, manitol, lisina y hierro (Atlas, 2005). Las pruebas bioquímicas fueron incubadas por 10 días a $28^{\circ} \mathrm{C}$.

Análisis estadísticos: fueron de tipo no paramétrico, ya que los datos de abundancia microbianas no cumplieron el requisito de normalidad (test de Shapiro-will=,0001; $\mathrm{p} \leq 0,05$ ). Para evaluar posibles diferencias en los valores de $\mathrm{NMP} / \mathrm{mL}$, variables físicas y químicas y la concentración de nutrientes entre las zonas del lago y durante las fechas de muestreo, se aplicaron el test de Kruskall Wallis; además, para observar diferencias específicas, se usaron el test de Mann Whitney y la prueba de Moses, con la corrección de Bonferroni $(\mathrm{p} \leq 0,005)$ (Kumari et al. 2011).

Para observar posibles asociaciones entre las variables físicas y químicas, las abundancias de las bacterias nitrificantes y las zonas y épocas de muestreo, se realizó un análisis de componentes principales, para datos categóricos y numéricas y una prueba de correlación de Spearman. El software estadístico utilizado para el análisis fue IBM SPSS Statistics (Base 22.0, 2013).

\section{RESULTADOS Y DISCUSIÓN}

Variables fisicoquímicas. En la figura 2, se observa el ACP, que explica el $71,7 \%$ de la varianza agrupada en los dos primeros componentes y con un valor $\alpha$ de Cronbach de 0,895 , valor aceptable de consistencia interna del análisis. El componente 1 (39,1\%), se asoció positivamente con la alcalinidad $(\mathrm{r}=0,527)$, el fósforo total $(r=0,629)$, los meses de muestreo $(r=0,895)$ y los valores de abundancia de BOA $(\mathrm{r}=0,613)$ y BON en caldo amonio $(\mathrm{r}=0,44)$. Por otro lado, al componente 1 , se relacionó negativamente a los valores de nitrógeno total $(\mathrm{r}-0,741)$. El componente 2 explica el $32,6 \%$ de la varianza de los datos y se vincula de forma positiva con la temperatura $(\mathrm{r}=0,609)$, la dureza $(\mathrm{r}=0,609)$, la conductividad eléctrica $(\mathrm{r}=0210)$, los valores de $\mathrm{NMP} / \mathrm{ml}$ de bacterias nitrificantes [BOA en caldo amonio $(r=0,48)$ y BON $(r=0,686)]$, mientras que variables, como el NID $(\mathrm{r}=-0,466)$ y $\mathrm{pH}(\mathrm{r}=0,-460)$, contribuyen negativamente al eje. El plano de ordenadas muestra la formación de tres grupos: Primer grupo asociado al componente uno, donde se describen la relación entre los meses de muestreo de agosto y septiembre (de menores precipitaciones), en los cuales, se registró un aumento de los valores de alcalinidad, de fósforo total (PT) y un aumento de los valores de $\mathrm{NMP} / \mathrm{ml}$ de bacterias nitrificantes, en zonas como Hato Laguna (zona 4), El Túnel (zona 5) y Lago Chico Custodia (zona 2). Un segundo grupo, en el plano de ordenadas (Figura 2), estuvo asociado al componente dos, en el cual, se encontró una relación en el aumento de la conductividad eléctrica, la dureza y el oxígeno disuelto, con una mayor abundancia de BOA y BON, en la zona de truchicultivo de Lago Grande El Túnel, durante el mes más lluvioso (julio). Los puntos de las zonas de truchicultivos en el plano cartesiano, se encuentran opuestos y alejados en el plano de los puntos de las zonas limnéticas centrales de lago Chico (zona 1) y Lago Grande (zona 3), es decir, algunas características físicas y químicas del agua, los nutrientes y la abundancia de bacterias nitrificantes es diferente entre estas zonas. Finalmente, se observó un tercero grupo, conformado por las concentraciones de $\mathrm{N}$ y $\mathrm{P}$ inorgánico cercanas a los valores del $\mathrm{pH}$ y las zonas limnéticas centrales del lago.

El nitrógeno total disminuyó durante los muestreos, con valores entre $1,78 \mathrm{mg} / \mathrm{L}$ a $1,87 \mathrm{mg} / \mathrm{L}$, para julio, en comparación con septiembre, de bajas precipitaciones, con valores de $1,68 \mathrm{mg} / \mathrm{L}$ a $1,74 \mathrm{mg} / \mathrm{L}$ (primer grupo de coordenadas, figura 2).

Se observaron diferencias estadísticamente significativas entre los valores de fósforo total de las zonas $(p=0,029$ de Mann Whitney; $\mathrm{p} \leq 0,05 ; \alpha=0,05)$, con concentraciones mayores en los sitios de truchicultivos (PT $=0,0734-0,0875 \mathrm{mg} / \mathrm{l}$ ) Las concentraciones de oxígeno son menores en las zonas con actividad piscícola $(4,09-$ $4,87 \mathrm{mg} / \mathrm{L})$ respecto a las demás zonas limnéticas centrales $(4,92$ $5,10 \mathrm{mg} / \mathrm{L}$ ) durante los meses más secos.

Por otra parte, se registraron diferencias estadísticamente significativas ( $p$ de Moses $=, 0001 ; p \leq 0,05 ; \alpha=0,05$ ), entre las fracciones inorgánicas de $\mathrm{N}$ y $\mathrm{P}$, de las zonas del lago, presentándose mayores concentraciones $(\mathrm{NID}=1,61-1,74 \mathrm{mg} / \mathrm{L} ; \mathrm{PID}=0,055-0,077 \mathrm{mg} / \mathrm{L})$, en los sitios de truchifactorias 
Tabla 1. Composición de los medios de cultivo utilizados en el aislamiento y cuantificación de bacterias nitrificantes.

\begin{tabular}{|c|c|}
\hline Medio de cultivo & Composición (g/L) \\
\hline $\begin{array}{l}\text { Medio para bacterias oxidantes de amonio (AOB) (Soriano \& } \\
\text { Walker, 1968; Koops \& Moller, 1992) }\end{array}$ & $\begin{array}{l}\mathrm{MgSO}_{4} \cdot 7 \mathrm{H}_{2} \mathrm{O}(0,04 \mathrm{~g}),\left(\mathrm{NH}_{4}\right)_{2} \mathrm{SO}_{4}(0,5 \mathrm{~g}), \mathrm{KH}_{2} \mathrm{PO}_{4}(0,2 \mathrm{~g}), \mathrm{CaCl}_{2} .2 \mathrm{H}_{2} \mathrm{O}(0,04 \mathrm{~g}) \text {, Agua desionizada } \\
(1 \mathrm{~L}) \cdot \mathrm{pH}=7,8-8,1\end{array}$ \\
\hline $\begin{array}{l}\text { Medio para bacterias oxidantes de nitritos (NOB) (Soriano \& } \\
\text { Walker, 1968; Koops \& Moller, 1992) }\end{array}$ & $\begin{array}{l}\mathrm{KNO}_{2}(0,3 \mathrm{~g}), \mathrm{MgSO}_{4} .7 \mathrm{H}_{2} \mathrm{O}(0,1875 \mathrm{~g}), \mathrm{KHCO}_{3}(1,5 \mathrm{~g}), \mathrm{K}_{2} \mathrm{HPO}_{4}(0,5 \mathrm{~g}), \mathrm{KH}_{2} \mathrm{PO}_{4}(0,5 \mathrm{~g}), \mathrm{NaCl} \\
(0,1875 \mathrm{~g}), \mathrm{CaCl} \cdot 2 \mathrm{H}_{2} \mathrm{O}(0,0125 \mathrm{~g}), \mathrm{FeSO} \cdot 7 \mathrm{H}_{2} \mathrm{O}(0,01 \mathrm{~g}) \text {, agua desionizada (1L). }\end{array}$ \\
\hline $\begin{array}{l}\text { Caldo Amonio para bacterias nitrificantes (Schmidt \& Belser, } \\
\text { 1982) }\end{array}$ & $\begin{array}{l}\left(\mathrm{NH}_{4}\right)_{2} \mathrm{SO}_{4}(0,5 \mathrm{a} 0,33 \mathrm{~g}), \mathrm{CaCO}_{3}(1 \mathrm{~g}), \mathrm{KH}_{2} \mathrm{PO}_{4}(1 \mathrm{~g}), \mathrm{MgSO}_{4}(0,3 \mathrm{~g}), \mathrm{NaCl}(0,3 \mathrm{~g}), \mathrm{FeSO}_{4}(0,03 \mathrm{~g}), \text { Agar- } \\
\text { agar }(18 \mathrm{~g}) \text { (Si es medio sólido), Agua desionizada (1L) }\end{array}$ \\
\hline Medio Winogradsky (Atlas, 2005) & $\begin{array}{l}1 \mathrm{~g} \mathrm{~K} \mathrm{HPO}_{4}, 2 \mathrm{~g} \text { de } \mathrm{NaCl}, 2 \text { a } 0,5 \mathrm{~g} \text { de } \mathrm{MgSO}_{4} .7 \mathrm{H}_{2} \mathrm{O}, 0,001 \mathrm{~g} \text { de } \mathrm{FeSO}_{4} .7 \mathrm{H}_{2} \mathrm{O}, 0,0,002 \text { de } \mathrm{CaCl}_{2} .2 \mathrm{H}_{2} \mathrm{O} \text {, } \\
1 \mathrm{~g} \text { de }\left(\mathrm{NH}_{4}\right)_{2} \mathrm{SO}_{4}, 1 \mathrm{~L} \text { de agua desionizada. }\end{array}$ \\
\hline Medio Winodgradsky - Modificado (Atlas, 2005) & $\mathrm{CaCO}_{3}(5 \mathrm{~g}),\left(\mathrm{NH}_{4}\right)_{2} \mathrm{SO}_{4}(1 \mathrm{~g}), \mathrm{K}_{2} \mathrm{HPO}_{4}(1 \mathrm{~g}), \mathrm{NaCl}_{(1 \mathrm{~g})}, \mathrm{MgSO}_{4} .7 \mathrm{H}_{2} \mathrm{O}(0,5 \mathrm{~g}), \mathrm{FeSO}_{4}(0,4 \mathrm{~g})$ \\
\hline Medio Nitrosomonas (Atlas, 2005) & $\begin{array}{l}\left(\mathrm{NH}_{4}\right)_{2} \mathrm{SO}_{4}(3 \mathrm{~g}), \mathrm{K}_{2} \mathrm{HPO}_{4}(0,5 \mathrm{~g}), \mathrm{MgSO}_{4} .7 \mathrm{H}_{2} \mathrm{O}(0,05 \mathrm{~g}), \mathrm{CaCl}_{2} .2 \mathrm{H}_{2} \mathrm{O}(4 \mathrm{mg}), \text { Rojo Cresol }(0,0005 \% \\
\text { sln) }(25 \mathrm{~mL}) \text {, Solución EDTA Férrico }(0,1 \mathrm{~mL}) \text {, ajustar el medio a un pH } 8,2-8,4 \text { a } 25^{\circ} \mathrm{C} \text {. Preparación } \\
\text { del medio: Agregar el sulfato de magnesio heptahidratado y dicloruro de calcio en agua destilada/ } \\
\text { ionizada y llevar a un volumen de } 500 \mathrm{~mL} \text {. Mezclar. En un frasco separado, agregar los demás com- } \\
\text { ponentes en agua destilada/ionizada y llevar a un volumen de } 500 \mathrm{~mL} \text {. Mezclar. Autoclavar ambas } \\
\text { soluciones por separado. Almacenar a } 25^{\circ} \mathrm{C} \text {. Bajo condiciones de asepsia, en cámara de flujo lami- } \\
\text { nar, combinar las dos soluciones estériles. Mezclar homogéneamente. Distribuir en tubos estériles. } \\
\text { Después de la inoculación, mantener un pH de } 8,2-8,4 \text { con solución estéril de } \mathrm{K}_{2} \mathrm{CO}_{3} \text { al } 50 \% \text {. }\end{array}$ \\
\hline
\end{tabular}

Cuantificación de bacterias nitrificantes. No existieron diferencias estadísticamente significativas de las abundancias de las poblaciones entre las zonas de muestreo ( $p=, 621 \mathrm{BOA} ; p=785 \mathrm{BON}$; $\mathrm{p} \leq 0,05 ; \alpha=0,05)$, al aplicar test de Kruskall Wallis; sin embargo, sí hubo variabilidad en las cuantificaciones bacterianas entre zonas particulares, mediante la prueba de Moses ( $\mathrm{p} \leq, 0001)$. Las abundancias de BOA registran diferencias entre lago Grande Centro $\left(3,6 \times 10^{3}-\right.$ $\left.7,5 \times 10^{4} \mathrm{NMP} / \mathrm{mL}\right)$ frente a lago Chico $\left(9,2 \times 10^{3}-2,4 \times 10^{5} \mathrm{NMP} / \mathrm{mL}\right)$ y lago Grande Hato Laguna $\left(9,2 \times 10^{3}-2,4 \times 10^{5} \mathrm{NMP} / \mathrm{mL}\right)$. Durante julio, en lago Grande Centro, se registraron las cuantificaciones más bajas de BOA, con relación a las demás zonas limnéticas (Figura 3). Ha sido documentado que las características de las zonas limnéticas centrales de los lagos, como mayores profundidades, alejamiento a las zonas litorales y altos porcentajes de saturación de oxígeno, causan bajas concentraciones de amonio, en las capas superficiales (Hernández et al. 2013) y, por ende, pueden influir en cuantificaciones bajas de bacterias nitrificantes en las zonas limnéticas, ya que el amonio es un nutriente limitante para las poblaciones de las BOA (French $e t$ al. 2012). En ecosistemas de mayores altitudes, las abundancias de las poblaciones $\mathrm{BOA}$ pueden ser influenciadas por factores, como la temperatura, el $\mathrm{pH}$, las concentraciones de amonio y la luz (Koops et al. 2006; French et al. 2012).

En general, se obtuvieron valores altos de bacterias nitrificantes $\left(\mathrm{BOA}=3,6 \times 10^{3}-\geq 2,4 \times 10^{6} \mathrm{NMP} / \mathrm{mL}, \mathrm{BON}=1,5 \times 10^{4}-1,1 \times 10^{6}\right.$ $\mathrm{NMP} / \mathrm{mL}$ ), con relación a otros lagos oligotróficos, como el lago Szelag Wielki, con $1-4 \times 10^{4} \mathrm{NMP} / \mathrm{mL}$ de BOA, $0-1 \times 10^{3} \mathrm{NMP} / \mathrm{mL}$ de $\mathrm{BON}$ y $88 \%$ de $\mathrm{BOA}$, en las muestras examinadas, con base al análisis de los genes de la monooxigenasa amoniaco (amo $A$ ), en nueve lagos, a altitudes de 2.289-3.160m (Lewandowska et al. 2003; Hayden \& Beman, 2014).

Se ha documentado que los lagos de alta montaña tienen una mayor abundancia de bacterias nitrificantes (Hayden \& Beman, 2014) respecto a otros ecosistemas acuáticos, debido a sus particularidades de la columna de agua, como $\mathrm{pH}$ alcalinos y altas concentraciones de oxígeno, factores que han sido descritos para el lago de Tota (González et al. 2008). 

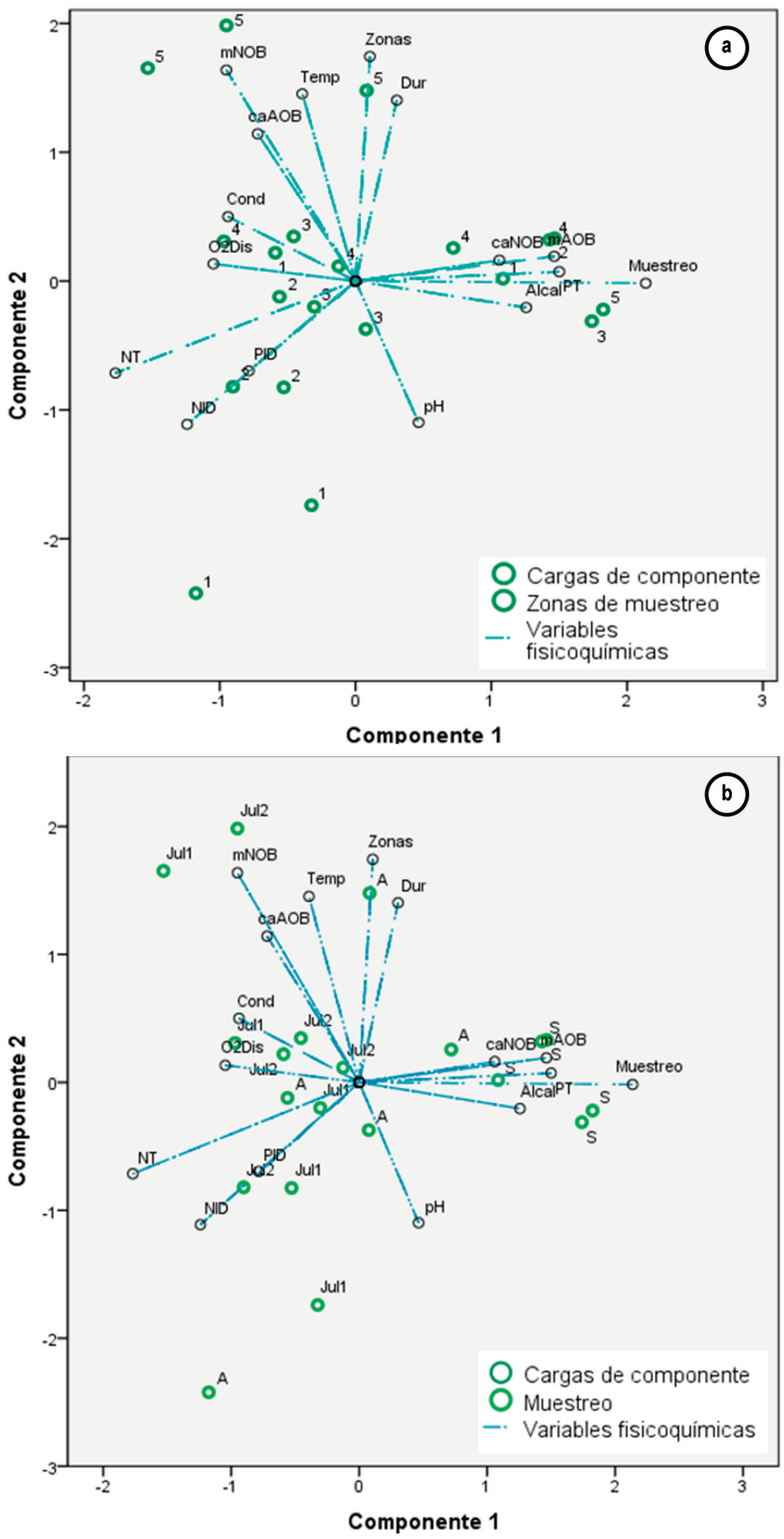

Figura 2. Análisis de componentes principales (ACP) para las variables físicas y químicas relacionadas con: a) zonas de muestreo y b) meses de muestreo Dur. Dureza; Alcal. Alcalinidad; Temp. Temperatura; Cond. Conductividad eléctrica; OxigDis. Oxígeno disuelto; SatO. Saturación de oxígeno; NT. Nitrógeno total; NID. Nitrógeno inorgánico disuelto; PT. Fósforo total; PID. Fósforo inorgánico disuelto; 1. Lago Chico Centro; 2. Lago Chico Custodia; 3. Lago Grande Centro; 4. Lago Grande Hato Laguna; 5. Lago Grande El Túnel; Jul1, Jul2. Tiempo de muestreo en julio; A. agosto; S. septiembre. 


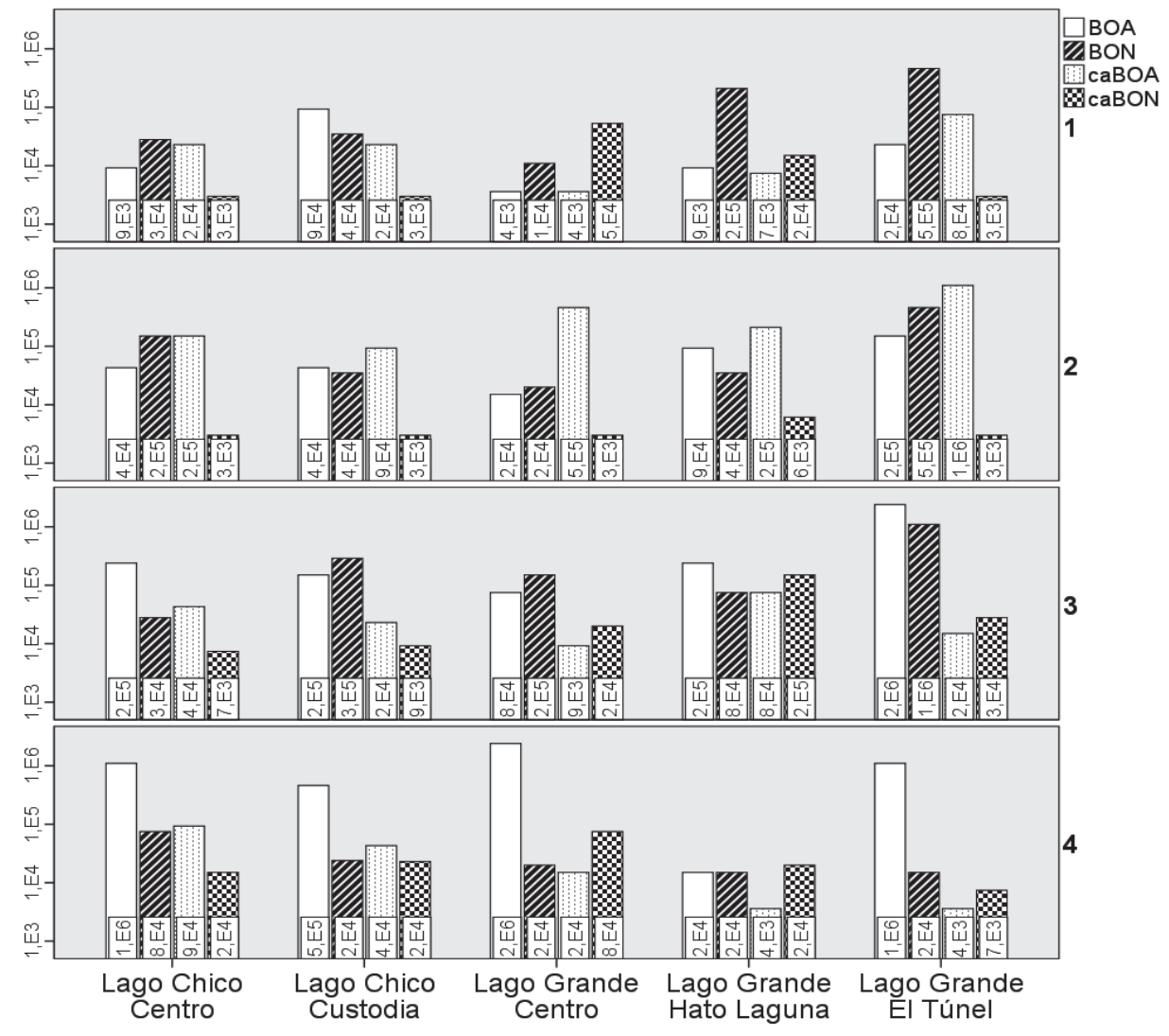

Figura 3. Abundancia de bacterias nitrificantes del Lago de Tota, durante periodo de lluvias. Eje Y. Abundancia (NMP/mL) a escala logarítmica; BOA. Bacterias oxidantes de amonio; BON. Bacterias oxidantes de nitritos; caBOA. Bacterias oxidantes de amonio en caldo amonio; caBON. Bacterias oxidantes de nitritos en caldo amonio; 1,2. Julio; 3. Agosto; 4. septiembre

Las abundancias de BOA y BON variaron entre lago Chico la Custodia, las zonas de truchifactoria (El Túnel y Hato Laguna) y los sitios limnéticos centrales de lago Grande, como se observó en las distancias euclidianas de los puntos en el análisis de componentes principales. En los meses más lluviosos, durante julio, registrado como el mes más lluvioso para el lago, los valores de BON en lago Grande Centro $\left(1,1 \times 10^{4}-1,5 \times 10^{5} \mathrm{NMP} / \mathrm{mL}\right)$ fueron bajos con relación a las cuantificaciones registradas en lago Chico la Custodia $\left(3,5 \times 10^{4}-2,9 \times 10^{5} \mathrm{NMP} / \mathrm{mL}\right)$ y zonas con actividad piscícola $\left(4,6 \times 10^{5}-\right.$ $1,1 \times 10^{6} \mathrm{NMP} / \mathrm{mL}$ ) (Figura 2). En general, Las bacterias nitrificantes (BOA y NOB) fueron más abundantes en las zonas con actividad piscícola $\left(3,6 \times 10^{3}-\geq 2,4 \times 10^{6} \mathrm{BOA}, 2 \times 10^{4}-1,1 \times 10^{6} \mathrm{BON} \mathrm{NMP} / \mathrm{mL}\right)$, respecto a los otros lugares muestreados y se relacionaron con los valores de conductividad eléctrica y dureza de las zonas. Kumari et al. (2011), en la columna de agua de estanques utilizados para cultivos de peces, reportaron $1,29 \times 10^{3}-1,67 \times 10^{3} \mathrm{NMP} / \mathrm{mL}$, de BOA y $1 \times 10^{3}$ $1,3 \times 10^{3} \mathrm{NMP} / \mathrm{mL}$, de $\mathrm{BON}$, valores bajos comparados a los del lago de Tota. Las BOA pueden utilizar el amoniaco excretado por los peces y minimizar los riesgos que tiene la acumulación del ion al ser tóxico en altas concentraciones y reducir los efectos de eutrofización (Xia et al. 2004). El número de las BOA, se correlaciona, de forma directa, con el grado de eutrofización de las aguas y a las mayores concentraciones de amonio. Lo anterior, ha sido corroborado en investigaciones, en las cuales, se reportan una mayor cuantificación de $\mathrm{BOA}$ en ambientes acuáticos con altas concentraciones de $\mathrm{NH}_{4}{ }^{+}$, provenientes de diversos procesos de contaminación (Kumari et al. 2011).

Existieron diferencias estadísticamente significativas entre los valores de abundancia de BOA en caldo amonio ( $p=013 ; \mathrm{p} \leq 0,05 ; \alpha=0,05)$, medio BOA $(p=, 015 ; p \leq 0,05 ; \alpha=0,05)$ y BON en caldo amonio $(\phi=, 020 ; p \leq 0,05 ; \alpha=0,05)$, durante los meses de muestreo, siendo evidente el aumento de las poblaciones en agosto y septiembre, de bajas precipitaciones (Figura 3). Asimismo, se observó en el ACP una relación del aumento de las bacterias nitrificantes con los valores de alcalinidad y de fósforo total. En el mes de bajas precipitaciones, los valores de $\mathrm{BOA}\left(1,5 \times 10^{4}-2,4 \times 10^{6} \mathrm{NMP} / \mathrm{mL}\right)$ fueron mayores, frente a los registrados en los meses más lluviosos $\left(3,6 \times 10^{3}-1,5 \times 10^{5}\right.$ $\mathrm{NMP} / \mathrm{mL}$ ), en cuatro de las cinco zonas. Los valores de BON en caldo amonio, se comportaron de igual forma, al ser mayores en el mes más seco $\left(1,5 \times 10^{4}-7,5 \times 10^{4} \mathrm{NMP} / \mathrm{mL}\right)$, con relación a los registrados en el más lluvioso $\left(\leq 3,0 \times 10^{3}-2,8 \times 10^{4} \mathrm{NMP} / \mathrm{mL}\right)$, para cuatro zonas del lago. La relación entre el número de bacterias nitrificantes y periodos secos también fue descrita por Rodríguez \& Valencia (2006), para las poblaciones del humedal Jaboque, Cundinamarca. El único estudio previo de estos grupos microbianos 
en el lago de Tota fue el realizado por Briceño et al. (2009), en el que cuantificaron BOA y BON de los sedimentos y sobrenadantes de la zona litoral, informando mayores poblaciones de BON en comparación a las BOA y hallaron una mayor abundancia de ambos grupos, en época de altas precipitaciones. Al comparar los resultados de esta investigación con los hallados en la zona limnética, se observa un comportamiento distinto de las poblaciones, ya que las BOA conforman poblaciones más altas respecto a las BON en la columna de agua, lo cual, podría estar asociado a las condiciones de oxígeno contrastantes entre los sedimentos, donde existen ambientes microaerófilos anaerobios más óptimos para las BON (Abeliovich, 2006), respecto a la columna de agua, donde las concentraciones de oxígeno son mayores con ambientes aerobios aptos para el metabolismo de BOA (Koops et al. 2006).

Las abundancias de BOA y BON pueden influir sobre las concentraciones de amonio y nitritos de los ecosistemas acuáticos (Whitby et al. 2001), por lo tanto, durante los meses más lluviosos, donde las poblaciones de BOA son más bajas, pueden aumentar los niveles de amonio, debido a la disminución de las BOA y en meses secos sucedería lo inverso, ya que aumentaría el consumo por parte del fitoplancton y las poblaciones microbianas nitrificantes. De esta forma, se acumula iones nitritos cuando se presenta un mayor número de BOA y menor de BON (Kumari et al. 2011); sin embargo, las variaciones en los valores del nutriente dependen también del consumo por parte del fitoplancton y de fuentes alóctonas. Briceño et al. (2009) documentaron un mayor número de bacterias oxidantes de nitritos frente a oxidantes de amonio en los sedimentos, lo que podría estar causando una acumulación de amonio al no ser oxidado e igualmente de nitratos que estarían aumentando su concentración y estar relacionados con procesos de eutrofización en las zonas litorales del lago, donde ocurren los principales procesos de descarga de contaminantes por los afluentes y, por consiguiente, de compuestos nitrogenados al ecosistema (Abella \& Martínez, 2012).
Relación de abundancia de bacterias nitrificantes (BOA, BON) y variables físicas y químicas. Existe una correlación media entre las concentraciones de fósforo total y las poblaciones de BON (Tabla 2). La abundancia de BON tiene una correlación baja inversa con los valores de $\mathrm{pH}$ en las zonas de Lago Chico Custodia y las zonas limnéticas de Lago Grande (Tabla 2). Las bacterias nitrificantes son alcalinófilas, ya que su crecimiento es óptimo a $\mathrm{pH}$, entre 7 a $8 \mathrm{y}$, valores menores a 6 , pueden inhibir su metabolismo (French et al. 2012); sin embargo, para julio y agosto, en Lago Grande Hato Laguna, se midieron $\mathrm{pH}$ por debajo de 7 . Este tipo de correlación directa entre los $\mathrm{pH}$ básicos y BOA también es registrado en los trabajos de Kumari et al. (2011) y French et al. (2012), para ecosistemas dulceacuícolas.

Se observó una correlación positiva entre los valores de BON y de conductividad eléctrica registrados en las estaciones de piscifactorías (Tabla 2). Se ha descrito que, a mayor cantidad de sólidos disueltos totales, incrementa el número de bacterias nitrificantes (Xia et al. 2004), ya que dentro de la fracción de iones que hacen parte de los sólidos disueltos se encuentran el amonio y el nitrito, la principal fuente de energía en el metabolismo de las bacterias nitrificantes (Xia et al. 2004).

Se evidenció una correlación positiva entre la alcalinidad y las poblaciones de BOA y BON (Tabla 2), observado durante el tiempo de muestreo y asociado a los cambios en las precipitaciones. Los valores de las poblaciones de bacterias nitrificantes, se correlacionaron con las concentraciones de $\mathrm{N}$ y $\mathrm{P}$ (Tabla 2). La abundancia de $\mathrm{BOA}$, se correlaciona negativamente con las concentraciones de fósforo inorgánico disuelto, que podría ser explicada por posible competencia con el fitoplancton por el nutriente. Canosa \& Pinilla (2007) registraron, en ecosistemas lénticos de alta montaña de Colombia, que el bacterioplancton disminuye cuando las clorofíceas aumentan, demostrando algún fenómeno de competencia entre las

Tabla 2. Correlaciones significativas entre las abundancias de bacterias nitrificantes con las variables físicas y químicas del Lago de Tota, Boyacá.

\begin{tabular}{|c|c|}
\hline $\begin{array}{c}\text { Variable-Grupo } \\
\text { microbiano }\end{array}$ & $\begin{array}{c}\text { Valor rho (r) de } \\
\text { Spearman y } p \\
\text { estadístico }\end{array}$ \\
\hline Alcal-BOA & $r=, 637 ; p=, 003^{* *}$ \\
\hline PID-BOA & $r=-, 457 ; p=, 043^{*}$ \\
\hline PT-BON & $r=, 477 ; p=, 034^{*}$ \\
\hline Cond-BON & $r=, 451 ; p=, 046^{*}$ \\
\hline NID-BON & $r=, 475 ; p=, 034^{*}$ \\
\hline pH-BON & $r=-, 340 ; p=, 040^{*}$ \\
\hline
\end{tabular}

Alcal. Alcalinidad; Cond. Conductividad eléctrica; $\mathbf{O}_{2}$ Dis. Oxígeno disuelto; SatO. Saturación de oxígeno; PT. Fósforo total; Jul1. julio primer muestreo; Jul2. julio segundo muestreo; Ago. Agosto; Sept. Septiembre; Alcal. Alcalinidad; NID. Nitrógeno inorgánico disuelto; PID. Fósforo inorgánico disuelto; (BOA). Bacterias oxidantes de amonio; (BON). Bacterias oxidantes de nitritos.

*Correlación estadísticamente significativa en el nivel $\alpha=0,05(p<0,05)$

**Correlación estadísticamente significativa en el nivel $\alpha=0,01 \quad(p<0,01)$ 
dos comunidades, posiblemente, asociado al fósforo que, al estar en menor concentración en los lagos, influye, principalmente, en la producción primaria.

Los valores para $\mathrm{BON}$ registrados durante el mes de mayor precipitación (julio), se correlacionan directamente con los de nitrógeno inorgánico disuelto (NID), lo cual, se puede relacionar a que las BON poseen un metabolismo con una cinética enzimática de primer orden, dado que, a medida que aumenta el sustrato -concentraciones de amonio-, el crecimiento poblacional es mayor (French et al. 2012). El NID constituye la fuente de energía para el metabolismo de BOA y BON (Koops et al. 2006).

Caracterización de las bacterias nitrificantes. Se lograron 14 aislamientos de bacterias nitrificantes en los medios Winodgrasky, Nitrosomonas spp. y Nitrobacter spp. Para BOA y BON, se obtuvieron nueve y cinco aislamientos, respectivamente, de los géneros Nitrosomonas y Nitrobacter (Puzyr et al. 2001; Kouki et al. 2011). La gran mayoría de morfotipos de BOA y BON de las zonas limnéticas centrales presentaron capacidad de hidrolizar urea, mientras que los aislamientos obtenidos de las zonas con actividad piscícola fueron negativos para esta hidrólisis. De los nueve aislamientos de BOA obtenidos en nuestro estudio, seis se consiguieron de las zonas limnéticas centrales de lago Chico y lago Grande, con respuesta ureasa positiva. Esta respuesta fisiológica microbiana ha sido asociada a BOA de sistemas oligotróficos (Koops \& PommereningRöser, 2001) y tres aislados en la columna de agua de truchicultivos, con respuesta de ureasa-negativa, se han relacionado a sistemas eutrofizados. Koops et al. (2006) clasifican a las BOA cultivables en linajes taxonómicos, de acuerdo con pruebas bioquímicas y que relacionan la actividad ureasa con el grado de eutrofización de las aguas donde habitan. La mayoría de las poblaciones nitrificantes que se aislaron de las zonas limnéticas centrales hidrolizan urea, descarboxilan y desaminan la lisina, fermentan compuestos orgánicos, crecen a altas concentraciones de sales y son móviles, perfiles bioquímicos, descritos para estos grupos bacterianos (Kouki et al. 2011). Estos caracteres ecofisiológicos funcionan como una adaptación a estados oligotróficos de los sistemas acuáticos (Koops et al. 2006).

Se encontró que el lago de Tota registró una alta concentración de bacterias nitrificantes, pero su abundancia varía entre las zonas de muestreo, siendo más abundantes en zonas de cultivo de trucha arcoíris y más bajas en las zonas limnéticas centrales y se correlacionaron a los valores del $\mathrm{pH}$, el fósforo total y la conductividad eléctrica. A su vez, la abundancia de BOA y BON varía durante las épocas de muestreo, aumentando en el mes con bajas precipitaciones y se correlacionan a cambios en la alcalinidad y del nitrógeno inorgánico disuelto, respectivamente. Se obtuvieron 14 aislamientos relacionados a los géneros Nitrosomonas y Nitrobacter.

Una mayor abundancia de las comunidades bacterianas y el registro de actividad ureasa negativa en los aislamientos obtenidos en Hato Laguna y el Túnel, zonas de producción piscícola, son elementos bioindicadores de la alteración del estado trófico del lago, a causa de la entrada de nitrógeno alóctono. La abundancia de las bacterias nitrificantes del lago, se correlacionaron con los valores de conductividad eléctrica y dureza de las zonas de truchifactorias. De igual forma, la abundancia aumenta durante los meses de bajas precipitaciones y se correlacionó al aumento de la alcalinidad y el fósforo total. Se recomienda reducir la cantidad de concentrados en la alimentación de las truchas, la densidad de peces por estanque y explorar la investigación en el posible uso de las poblaciones nitrificantes cultivables en procesos de biorremediación, de las zonas afectadas.

Agradecimientos. El trabajo fue financiado por la convocatoria Capital Semilla, No.1 de 2015 de la dirección de Investigación (DIN) de la Universidad Pedagógica y Tecnológica de Colombia (UPTC). Los autores no declaramos conflicto de intereses.

\section{REFERENCIAS}

1. ABELLA, G.; MARTÍNEZ, C.J. 2012. Contribución de un afluente tributario a la eutrofización del Lago de Tota (Boyacá, Colombia). Revista Colombiana de Química (Colombia). 41(2):243-261.

2. ABELIOVICH, A. 2006. The Nitrite-Oxidizing Bacteria. En: Dworkin, M.; Falkow, S.; Rosenberg, E.; Schleifer, K.H.; Stackebrandt, E.; (eds). The Prokariotes: A Handbook on the Biology of Bacteria. $3^{\mathrm{a}}$ ed. Volumen 5: Proteobacteria: Alpha and Beta Subclasses. Springer Science Business Media (Luxemburgo, Alemania). p.861-872. https://doi. org /10.1007/0-387-30745-1-41

3. AMERICAN PUBLIC HEALTH ASSOCIATION, APHA. 2012. Standard Methods for the Examination of Water and Wastewater. 22 ed (Virginia, Estados Unidos). p.1323-1326.

4. ATLAS, R.M. 2005. Handbook of Media for environmental Microbiology. University of Louiswille Estados Unidos). Ed. CRC Press. p.848-950.

5. BOCK, E.; KOOPS, H.P. 1992. The genus Nitrobacter and related genera. En: Ballows, A.A.; Truper, H.G.; Dworkin, M.; Harder, W.; Schleifer, K.H. (eds). The Prokaryotes. Ed. Springer-Verlag, N.Y. p.2302-2309.

6. BRICEÑO, F.J; CAMARGO, M.P.; LIZARAZO-FORERO, L.M. 2009. Bacterias asociadas a la transformación del Nitrógeno en la zona Litoral del Lago de Tota-AquitaniaBoyacá. Suelos Ecuatoriales (Colombia). 39(1):29-33.

7. CANOSA, A.; PINILLA, G. 2007. Relaciones entre las abundancias del bacterioplancton y del fitoplancton en tres ecosistemas lénticos de los Andes Colombianos. Rev. Biología Tropical (Costa Rica). 55(1):135-146.

8. FRENCH, E.; KOZLOWSKI, J.A.; MUKHERJEE, M.; BULLERJAHN, G.; BOLLMANN, A. 2012. 
Ecophysiological characterization of ammonia-oxidizing archaea and bacteria from freshwater. Applied and Environmental Microbiology (Estados Unidos). 78:57735780. https://doi.org/10.1128/AEM.00432-12

9. GONZÁLEZ, A.A.; ARANGUREN-RIAÑO, N.; GAVIRIA, S. 2008. Cambios en la estructura de la población de Boeckella gracilis (Crustacea, Centropagidae) en el plancton del lago de tota, Boyacá - Colombia. Acta Biológica Colombiana (Colombia). 13:61-72. http://dx.doi.org/10.15446/abc

10. HERNÁNDEZ, E.; AGUIRRE, N.; PALACIO, J.; RAMÍREZ, J.J.; DUQUE, S.R.; GUISANDE, C.; ARANGUREN, N.; MOGOLLÓN, M. 2013. Evaluación comparativa de algunas características limnológicas de seis ambientes leníticos de Colombia. Rev. Fac. Ing. U.de Antioquia (Colombia). 69:216-228.

11. HAYDEN, C.J.J.; BEMAN, M. 2014. High Abundances of Potentially Active Ammonia- Oxidizing Bacteria and Archaea in Oligotrophic, High-Altitude Lakes of the Sierra Nevada, California, USA. PLOS ONE (Estados Unidos). 9(11):1-9. https://doi.org/10.1371/journal.pone.0111560

12. KOOPS, H.P.; MOLLER, U.C. 1992. The lithotrophic ammoniaoxidizing bacteria. En: Ballows, A.; Truper, H.G.; Dworkin, M.; Harder, W.; Schleifer, K.H. (eds). The Prokaryotes. Ed. Springer-Verlag (N. Y.). p.711-811.

13. KOOPS, H.P.; POMMERENING-RÖSER, A. 2001. Distribution and ecophysiology of the nitrifying bacteria emphasizing cultured species. Microbial Ecology (Alemania). 37:1-9. https://doi.org/10.1111/j.1574-6941.2001. tb00847.x

14. KOOPS, H.P.; PURKHOLD, U.; POMMERENINGRÖSER, A.; TIMMERMANN, G.; WAGNER M. 2006. The Lithoautotrophic Ammonia-Oxidizing Bacteria. En: Dworkin, M.; Falkow, S.; Rosenberg, E.; Schleifer, K.H.; Stackebrandt, E. (eds). The Prokariotes: A Handbook on the Biology of Bacteria. 3 ed. Volumen 5: Proteobacteria: Alpha and Beta Subclasses. Ed. Springer. p.778-812. https://doi.org/10.1007/0-387-30745-1_36

15. KOUKI, S.; SAIDI, N.; M'HIRI, F.; NASR, H.; CHERIF, H.; OUZARI, H.; HASSEN, A. 2011. Isolation and characterization of facultative mixotrophic ammoniaoxidizing bacteria from constructed wetlands. J. Environmental Sciences (Paises bajos). 23(10):1699-1708. https:/ /doi.org/10.1016/S1001-0742(10)60596-7

16. KUMARI, V.; RATHORE, G.; CHAUHAN, U.K.; PANDEY, A.K.; LAKRA, W.S. 2011. Seasonal variations in abundance of nitrifying bacteria in fish pond ecosystem. J. Environmental Biology (India). 32(2):153-159.
17. LEWANDOWSKA, D.; GOLAŚ, I.; ZMYSEOWSKA, I.; TEODOROWICZ, M. 2003. Active bacteria in transitions of nitrogen compounds in pond water during the wintering of European catfish (Silurus glanis L.) fry. Polish J. Natural Sciences. (Polonia). 14(2):511-522.

18. MUÑOZ-LÓPEZ, C.L.; ARANGUREN-RIAÑO, N.J.; DUQUE, S.R. 2017. Morfología funcional del fitoplancton en un lago de alta montaña tropical: Lago de Tota (BoyacáColombia). Rev. Biología Tropical. 65(2):669-683. https:// doi.org/10.15517/rbt.v65i2.23903.

19. PUZYR, A.P.; MOGIL'NAYA, O.A.; GUREVICH, Y.L.; BABKINA, E.A. 2001. Colony Structure of a Consortium of Nitrifying Bacteria. Microbiology. (Reino Unido). 70(1):84-90. https://doi.org/10.1023/A:1004853123326

20. RODRÍGUEZ, A.A.; VALENCIA, H. 2006. Estimación de poblaciones de microorganismos del ciclo del nitrógeno y su relación con el grado de eutroficación del humedal Jaboque, Cundinamarca, Colombia. Acta Biológica Colombiana.11(1):133-176. http://dx.doi.org/10.15446/abc

21. UNIDAD DE ECOLOGÍA EN ECOSISTEMAS ACUÁTICOS- UDESA-UPTC; CORPORACIÓN AUTÓNOMA REGIONAL DE BOYACACORPOBOYACÁ. 2015. Efecto de la variabilidad climática de un ciclo anual sobre el flujo de nutrientes (C, N y P), fuentes y biocaptación en el Lago de Tota. Informe final - Convenio 092 de 2015 Uptc \& Corpoboyacá. p. 41-55.

22. SCHMIDT, E.L.; BELSER, L.W. 1982. Nitrifying bacteria. En: Methods of Soil Analysis. Part 2, Chemical and Microbial Properties- Agronomy Monograph (Estados Unidos) No 9. 48:1027-1041.

23. SORIANO, S.; WALKER, N. 1968. Isolation of ammoniaoxidizing autotrophic bacteria. J. Appl. Bacteriol. 31(4):493497.

24. WHITBY, C.B.; SAUNDERS, J.R.; PICKUP, R.W.; MCCARTHY, A.J. 2001. A comparison of ammonia-oxidiser populations in eutrophic and oligotrophic basins of a large freshwater lake. Antonie Van Leeuwenhoek (Alemania). 79:179-188. https://doi.org/10.1023/A:1010202211368

25. XIA, X.H.; YANG, Z.F.; HUANG, G.H.; ZHANG, X.Q.; YU, H.; RONG, X. 2004. Nitrification in natural waters with high suspended-solid content-A study for the Yellow River. Chemosphere (Holanda). 57(8):1017-1029. https:// doi.org/10.1016/j.chemosphere.2004.08.027 